\title{
Assessment of Conceptual Difficulties in Chemistry Syllabus of the Nigerian Science Curriculum as Perceived by High School College Students
}

\author{
Jack Gladys Uzezi*, Danjuma Ezekiel, Abdul-Kadir Musa Auwal \\ Department of Science Education, Taraba State University, P.M.B 1167, Jalingo, Nigeria \\ *Corresponding author: gjackuzezi@yahoo.com
}

\begin{abstract}
Poor performance in chemistry is an indication that students have difficulty in learning and mastering the content and applying these when they are under examination conditions. This study therefore was conducted to identify concepts perceived as difficult by chemistry students in Jalingo metropolis. One hundred and ninety eight SS3 or $12^{\text {th }}$ grade students were randomly selected from six secondary schools offering science subjects within Jalingo metropolis. The data collection tool was Chemistry Difficult Concepts Identification Questionnaires which consisted of two sections. Means and standard deviation where used to analyzed the data collected while t-test statistic was used to test the null hypotheses. Findings showed that the students perceived 12 concepts (63.16 \%) as difficult out of the 19 concepts in the questionnaire. Results based on gender showed that, the males perceived 15 (78.95\%) concepts in the SSS3 chemistry concepts as difficult, while the females perceived eleven (57.89\%) concepts as difficult. On the other hand, single-sex (boys only) perceived 17 concepts as difficult, girls only perceived 13 and co-educational perceived 12 concepts as difficult respectively. While students in rural and urban schools perceived each 11 varied concepts as difficult. The study also revealed that there was a significant influence of gender, school nature and school location on students' concepts perceived as difficult in the chemistry syllabus of the Nigerian science curriculum. It was however; recommended that more time should be allocated to chemistry for effective teaching of the identified difficult concepts and usage of student-oriented practical activities, as this would help to concretize learnt concepts and reduce poor performances of students in both internal and external examinations.
\end{abstract}

Keywords: conceptual difficulties, Nigerian science curriculum, perceived difficult concepts, chemistry syllabus

Cite This Article: Jack Gladys Uzezi, Danjuma Ezekiel, and Abdul-Kadir Musa Auwal, "Assessment of Conceptual Difficulties in Chemistry Syllabus of the Nigerian Science Curriculum as Perceived by High School College Students." American Journal of Educational Research, vol. 5, no. 7 (2017): 710-716. doi: 10.12691/education-5-7-3.

\section{Introduction}

Science education is essential as it is of immense value in the student's individual life and his life in society. The great value of science is that it has introduced us to new ways of thinking and reasoning. It is obligatory on the part of a science teacher to teach practical aspect of all the scientific principles and knowledge impacted to the students. The students should not only know about the scientific principles and facts, but should also be able to use them practically in understanding their self and environment surrounding them. There is no doubt that our National Policy on Education [2], places much emphasis on science education; particularly chemistry.

Chemistry is one of the most important branches of science; it enables learners to understand what happened around them. Because chemistry topics are generally related to or based on the structure of matter, chemistry proves a difficult subject for many students. Chemistry curricula commonly incorporate many abstract concepts, which are central to further learning in both chemistry and other sciences [12]. These abstract concepts are important because further chemistry/science concepts or theories cannot be easily understood if these underpinning concepts are not sufficiently grasped by the student [7]. The abstract nature of chemistry along with other content learning difficulties such as the mathematical nature of chemistry makes chemistry classes require a high-level skill set [12].

In Nigeria, chemistry is considered as an important subject and is taught in the last three years of secondary education usually called the senior secondary school (SSS) or $10^{\text {th }}$ grade class. It is taught as a single subject and the scope covered and understood within this period is questionable. In spite of the number of years chemistry has been taught in our secondary schools, it is noteworthy that little meaningful learning of chemistry concepts have taken place and this can be proved by students inability to apply already learnt concepts. Nigeria is a developing nation and the importance of chemistry for such a nation cannot be overemphasized. This is in line with the 
assertion that prestige and socio-economic power of any nation reside in its level of scientific activities. Jalingo metropolis is one of the towns in Nigeria which needs the attentions of the educators, government and the students alike to be paid to science due to the low level of the development in the metropolis. More so, for meaningful development to take place in the area, chemistry discipline must be made accessible to the students living within Jalingo area. Hence, a number of secondary schools offering science subjects including Chemistry has scattered in all the nooks and crannies of Jalingo Local Government Area. However, despite the prolific numbers of secondary schools offering science subjects, the outcome of Chemistry has not been properly harnessed and this issue could be due to the difficulty of the subject.

Consequently, there is a great need to help improve chemistry students' perceived learning difficulties of chemical concepts not just for them to sail through SSCE/GCE examinations, but also for them to be aware and be appreciative of the contributions they can make to the country's development. Available evidence from West African Examination Council and some science educationist $[4,10,15,16]$ indicated that student's poor academic achievement in chemistry. The findings from [14] also revealed that impediments to the effective teaching of Chemistry in secondary schools included lack of qualified Chemistry teachers, noisy environment, an unavailability of laboratory equipment and students' perception of Chemistry as a difficult subject with many theories.

Several studies in the chemistry education literature dealt with the learning difficulties of basic concepts of chemistry at schools. Concepts formed when the ideas or thoughts are developed based on common properties of objects or events by the process of abstraction. Conceptual difficulties was also identified by [9] from Nigerian Secondary School Pupils in electrolysis through concept inventory. Furthermore, in order to reduce the challenges students face when learning Chemistry, Students-centered cooperative learning strategies have been recommended as a superior alternative to the teacher dominated "stage on the stage" nature of the conventional lecture method.

The study carried out by [8] was on; "difficulties experienced in the learning of electrochemistry concepts" in University of Nigeria, Nsukka. The research design used in the study was ex-posed facto. A total of 400 grade II students were randomly selected from four secondary schools in the area. They used group embedded figure test to categorize the students into two cognitive styles; field depending group (266) students and field independent group (134 students). After they have exhaustively thought electrochemistry concepts for six weeks, the students or respondents were administered with electrochemistry diagnosis test. It was found that six broad areas of concepts posed considerable difficulties to majority of students.

The research work carried out by [14] was to identify topics the students perceived difficult in senior secondary school II Chemistry curriculum in Imo state using government secondary schools in Owerri Municipal Council of Imo state. Findings revealed that SS II Chemistry students perceived some Chemistry topics difficult. Chemistry syllabus being too wide and involving too many calculations; lack of qualified Chemistry teachers and students' perception of Chemistry as being too abstract are some of the reasons for the difficulties in understanding the topics.

The current WAEC/SSCE and National Examination Council, NECO/SSCE Syllabus on Chemistry cut across topics in physical, inorganic, Environmental and analytical Chemistry systematically arranged under nineteen topics. In the modern society, so much science careers and science base disciplines like Pharmacy, Agricultural science, Nursing, Medicine, Engineering, Laboratory technology and the likes require that science students must pass Chemistry at the Credit level in the Senior Secondary school Examination. Despite this demand, most of the few students who choose to offer Sciences in our secondary schools are noted for having problems learning the sciences especially Chemistry, which is manifested in poor performance in the examination (WAEC) $[15,16]$. Poor performance in Chemistry is an indication that students having difficulty in learning and mastering the content and applying these when they are under examination conditions.

This trend has posed a problem and concern to science educators, researchers and the students at large. Due to this problem, this study is intended to identify concepts perceived difficult by students in Jalingo metropolis in the senior secondary school certificate Chemistry syllabus. The general Purpose of the study therefore is to identify concepts perceived as difficult by Chemistry students in to learn and also find out the influence of gender, school Nature and school location on students' perception of difficult concepts in Chemistry syllabus.

The following research questions were raised to guide the study:

1. What are the concepts in the senior secondary school Chemistry syllabus that students perceive as difficult to learn?

2. Does gender influence students performance of difficult concepts?

3. Does school nature influence students' perception of difficult concepts in Chemistry syllabus?

4. Does school location influence students' perception in difficult concepts in Chemistry Syllabus at SSCE Level?

The following null hypotheses were also formulated and tested at; 0.05 level of significance:

$\mathbf{H}_{\mathbf{0 1}}$ Students' Gender has no significant difference in the students' perception of difficult concepts in the senior secondary school Chemistry syllabus.

$\mathbf{H}_{\mathbf{0} 2}$ School nature has no significant influence on students' perception of difficult concepts in chemistry at the secondary school level.

$\mathbf{H}_{\mathbf{O} 3}$ School location has no significant influence on students' perception of difficult concepts in chemistry at the secondary school level.

\section{Materials and Methods}

The type of design used for this study is survey research design. This was adopted because the study sought the opinion of the students through a questionnaire formed by the researchers on the identification of difficult concepts 
in senior secondary school certificate chemistry syllabus as perceived by students in Jalingo Metropolis.

A sample of one hundred and ninety eight SS3 chemistry students of 2015/2016 session were randomly selected from six secondary schools offering science subjects in Jalingo Metropolis. Nature of the school (single sex or co-educational), school location and gender difference among students are considered when choosing the sample. Due to that, 66 students out of the 198 samples are from single sex schools (i.e. only girls or only boys). Out of the 66 students, 26 are boys and the remaining 40 are girls. 132 students out of the 198 students are from coeducational schools (i.e. mixed-sex schools). A total of 175 students were reached in the selected schools in urban area and 23 students are reached in the selected rural schools. Purposive sampling technique was used to arrive at the sample; due to the absence of the chemistry teachers in some of the schools.

The main instrument used to collect data for the study was a concept inventory namely; Chemistry Difficulty concepts Identification Questionnaire (CDCIQ) constructed by the researchers. Section A of the questionnaire is on bio-data information such as, name of the school, nature of the school (i.e. single-sex or co-educational), location of school (i.e. rural or urban), gender of the respondent, and class of the respondent. Section B, consists of 19 major concepts or concepts in WASSCE/SSCE and NECO/SSCE chemistry syllabus, covering physical, organic, inorganic, environmental and practical Chemistry. The 19-items questionnaire was an adaptation of 3-point likert scale type. Respondents are asked to respond by ticking the appropriate responses; difficult (D) average (A) and easy (E) in the questionnaire.

The instrument was validated by two experienced lecturers one from science education and the other from chemistry department of Taraba State University, and two experienced chemistry teachers from two secondary schools. The questionnaire was subjected to test re-test method by pre-testing it using 30 SS II chemistry students in two randomly selected secondary schools in Jalingo Metropolis. Their responses; difficult (D), average (A), and easy (E) were assigned 3, 2 and 1 respectively. The data obtained was subjected to Kuder Richardson formula, KR-20 to obtain the correlation value. A correlation coefficient of 0.81 was obtained which was considered adequate for this study.

The researchers obtained permission from the authorities of the sampled schools before the administration of the instrument. The researchers guided the students on the response to the bio-data section of the CTAQ to fill in the information appropriately, while section $B$ of the questionnaire was left for the students to tick the topic or concept based on their perception of difficulty level. The filled questionnaires were collected by the researchers after the students had filled it.

The one hundred and ninety eight chemistry students from the six randomly selected secondary schools offering science subjects in Jalingo Metropolis completed the questionnaire and the data collected was analyzed using means, standard deviation, and t-test statistic. The level of difficulty of a particular topic or concept was determined by the value of means as follows: - means less than 1.76 $(0 \leq X \leq 1.75)$ easy and means between 1.76 and 3.0 (i.e. $1.76 \leq \mathrm{X} \leq 3.0)$ difficult.

\section{Results}

Answering Research questions:

Research Question one: What are the concepts in the senior secondary school Chemistry syllabus that students perceived as difficult to learn?

Research question I examined the difficulty level of chemistry concepts in the SSS chemistry syllabus as perceived by students. Table 1 was used to answer this research question. A summary of the mean scores and standard deviation is presented in Table 1.

Table 1 revealed that the students perceived twelve concepts in the SSS3 chemistry syllabus as difficult. This was seen from the mean values; that the students perceived 12 concepts (63.2\%) as difficult out of the nineteen chemistry topics or concepts as means between 1.76 and 3.00 were considered difficult. This showed the difficulty in the perception of the students on chemistry concepts was $63.2 \%$.

Table 1. Mean and standard deviation of difficult level of chemistry concepts

\begin{tabular}{|c|c|c|c|c|}
\hline $\mathbf{S} / \mathbf{N}$ & TOPICS OR CONCEPTS & MEAN & STANDARD DEVIATION & REMARK \\
\hline 1 & Separation of mixture & 1.49 & 0.65 & Not Difficult \\
\hline 2 & Particulate nature of matter & 1.66 & 0.76 & Not Difficult \\
\hline 3 & Symbols, formulae and equations & 1.85 & 0.74 & Difficult \\
\hline 4 & Chemical combination & 1.67 & 0.69 & Not Difficult \\
\hline 5 & Gaseous State & 1.60 & 0.70 & Not Difficult \\
\hline 6 & Acids, bases and salts & 1.77 & 0.72 & Difficult \\
\hline 7 & Carbon and its Compounds & 1.73 & 0.69 & Not Difficult \\
\hline 9 & Periodic tables of element & 1.69 & 0.74 & Not Difficult \\
\hline 10 & Structure and energy level of atom & 2.33 & 0.73 & Difficult \\
\hline 11 & Quantitative analysis & 2.24 & 0.75 & Difficult \\
\hline 12 & Rate of Chemical Reaction & 1.72 & 0.73 & Not Difficult \\
\hline 13 & Chemical Equation & 1.94 & 0.73 & Difficult \\
\hline 14 & Non metals and their compounds & 2.15 & 0.79 & Difficult \\
\hline 15 & Thermo chemistry & 2.49 & 0.69 & Difficult \\
\hline 17 & Applied chemistry & 2.52 & 0.69 & Difficult \\
\hline 18 & Nuclear chemistry & 2.33 & 0.77 & Difficult \\
\hline 19 & Astronomical chemistry & 2.65 & 0.65 & Difficult \\
\hline
\end{tabular}


Research Questions two: Does gender influence students' perception of difficult concepts in chemistry syllabus?

Table 2 was used to answer this research questions on perception of students on difficult concepts in chemistry syllabus based on students gender.

Table 2 showed the influence of students' gender on the perception of chemistry concepts. Considering the standard; mean between 1.76 and 3.00 are difficult, the males perceived fifteen (78.95\%) concepts in the SSS3 chemistry concepts as difficult, while the females perceived eleven (57.89\%) concepts as difficult. The standard deviation of the males mean scores ranged from 0.64-0.85 and that of the females' mean scores ranged from 0.55-0.79 revealing a marked difference in the perception of difficulty in chemistry concepts.

Research question three: Does school nature influence students' perception of difficult concepts in chemistry syllabus?

Table 3 was used to answer this research question.

Table 2. Influence of students' Gender on perception of chemistry concepts

\begin{tabular}{|c|c|c|c|c|c|c|c|}
\hline \multirow[b]{2}{*}{$\mathbf{S} / \mathbf{N}$} & \multirow[b]{2}{*}{ TOPICS OR CONCEPTS } & \multirow[b]{2}{*}{$\mathbf{N}$} & \multicolumn{2}{|c|}{ MALE } & \multicolumn{3}{|c|}{ FEMALE } \\
\hline & & & MEAN & SD & $\mathbf{N}$ & MEAN & SD \\
\hline 1 & Separation of mixture & 99 & 1.59 & 0.73 & 99 & 1.39 & 0.55 \\
\hline 2 & Particulate nature of matter & 99 & 1.76 & 0.85 & 99 & 0.57 & 0.66 \\
\hline 3 & Symbol, formulae and equation & 99 & 1.89 & 0.75 & 99 & 1.82 & 0.73 \\
\hline 4 & Chemical combination & 99 & 1.72 & 0.79 & 99 & 1.68 & 0.60 \\
\hline 5 & Gaseous state & 99 & 1.67 & 0.74 & 99 & 1.54 & 0.66 \\
\hline 6 & Acids, base and salts & 99 & 1.91 & 0.73 & 99 & 1.63 & 0.68 \\
\hline 7 & Carbon and its compounds & 99 & 1.79 & 0.74 & 99 & 1.67 & 0.64 \\
\hline 8 & Organic chemistry & 99 & 1.82 & 0.76 & 99 & 1.93 & 0.79 \\
\hline 9 & Periodic table of element & 99 & 1.64 & 0.80 & 99 & 1.74 & 0.68 \\
\hline 10 & Structure\& energy of atom & 99 & 2.40 & 0.73 & 99 & 2.25 & 0.72 \\
\hline 11 & Quantitative analysis & 99 & 2.23 & 0.75 & 99 & 2.24 & 0.76 \\
\hline 12 & Rate of chemical Reaction & 99 & 1.75 & 0.79 & 99 & 1.69 & 0.68 \\
\hline 13 & Chemical Equation & 99 & 1.93 & 0.76 & 99 & 1.95 & 0.71 \\
\hline 14 & Non-metal \& their Compounds & 99 & 2.22 & 0.78 & 99 & 2.08 & 0.79 \\
\hline 15 & Thermo-chemistry & 99 & 2.48 & 0.71 & 99 & 2.49 & 0.69 \\
\hline 16 & Metals and their compounds & 99 & 2.21 & 0.70 & 99 & 2.05 & 0.79 \\
\hline 17 & Applied chemistry & 99 & 2.56 & 0.67 & 99 & 2.47 & 0.72 \\
\hline 18 & Nuclear chemistry & 99 & 2.22 & 0.80 & 99 & 2.44 & 0.70 \\
\hline 19 & Astronomical chemistry & 99 & 2.65 & 0.64 & 99 & 2.65 & 0.66 \\
\hline
\end{tabular}

$\mathrm{N}=$ no of respondents, $\mathrm{SD}=$ Standard deviation.

Table 3. Influence of school nature on perception of chemistry concepts

\begin{tabular}{|c|c|c|c|c|c|c|c|c|c|c|}
\hline \multirow[b]{2}{*}{$\mathrm{S} / \mathbf{N}$} & \multirow[b]{2}{*}{ TOPICS OR CONCEPTS } & \multicolumn{4}{|c|}{ BOYS ONLY } & \multicolumn{2}{|c|}{ GIRLS ONLY } & \multicolumn{3}{|c|}{ CO-EDUCATION } \\
\hline & & $\mathbf{N}$ & MEAN & SD & $\mathbf{N}$ & MEAN & SD & $\mathbf{N}$ & MEAN & SD \\
\hline 1 & Separation of mixture & 26 & 1.81 & 0.85 & 40 & 1.50 & 0.55 & 132 & 1.43 & 0.62 \\
\hline 2 & Particulate nature of matter & 26 & 1.85 & 0.88 & 40 & 1.60 & 0.74 & 132 & 1.1 & 0.74 \\
\hline 3 & Symbol, formulae and equation & 26 & 2.23 & 0.59 & 40 & 1.85 & 0.74 & 132 & 1.78 & 0.75 \\
\hline 4 & Chemical combination & 26 & 1.69 & 0.74 & 40 & 1.73 & 0.59 & 132 & 1.68 & 0.72 \\
\hline 5 & Gaseous state & 26 & 1.85 & 0.61 & 40 & 1.53 & 0.64 & 132 & 1.58 & 0.73 \\
\hline 6 & Acids, base and salts & 26 & 1.96 & 0.72 & 40 & 1.33 & 0.53 & 132 & 1.86 & 0.72 \\
\hline 7 & Carbon and its compounds & 26 & 2.08 & 0.74 & 40 & 1. 85 & 0.53 & 132 & 1.63 & 0.70 \\
\hline 8 & Organic chemistry & 26 & 1.65 & 0.69 & 40 & 2.25 & 0.73 & 132 & 1.80 & 0.78 \\
\hline 9 & Periodic table of element & 26 & 1.77 & 0.86 & 40 & 2.90 & 0.63 & 132 & 1.61 & 0.74 \\
\hline 10 & Structure\& energy l. of atom & 26 & 2.31 & 0.74 & 40 & 1.25 & 0.71 & 132 & 2.36 & 0.73 \\
\hline 11 & Quantitative analysis & 26 & 2.38 & 0.75 & 40 & 1.28 & 0.72 & 132 & 2.20 & 0.77 \\
\hline 12 & Rate of chemical Reaction & 26 & 1.88 & 0.77 & 40 & 1.65 & 0.66 & 132 & 1.70 & 0.75 \\
\hline 13 & Chemical Equation & 26 & 1.88 & 0.77 & 40 & 2.85 & 0.66 & 132 & 1.98 & 0.75 \\
\hline 14 & Non metal \& their Compounds & 26 & 1.96 & 0.72 & 40 & 2.88 & 0.72 & 132 & 2.27 & 0.79 \\
\hline 15 & Thermo-chemistry & 26 & 2.50 & 0.65 & 40 & 2.50 & 0.72 & 132 & 2.48 & 0.69 \\
\hline 16 & Metals and their compounds & 26 & 2.04 & 0.66 & 40 & 2.00 & 0.78 & 132 & 2.19 & 0.75 \\
\hline 17 & Applied chemistry & 26 & 2.19 & 0.80 & 40 & 2.45 & 0.71 & 132 & 2.60 & 0.65 \\
\hline 18 & Nuclear chemistry & 26 & 2.35 & 0.85 & 40 & 2.58 & 0.64 & 132 & 2.26 & 0.79 \\
\hline 19 & Astronomical chemistry & 26 & 2.58 & 0.70 & 40 & 2.73 & 0.55 & 132 & 2.64 & 0.67 \\
\hline
\end{tabular}

$\mathrm{N}=$ No. of respondents, $\mathrm{SD}=$ Standard Deviation. 
Table 3 revealed the influence of school nature on students' perception of difficult concepts on SSS3 chemistry syllabus. Keeping with the values of mean between 1.76-3.00 as difficult, the single sex school (i.e. boys only or girls only) and co-educational school chemistry concepts are as follows: Single sex school (boys only) students perceived seventeen concepts as difficult and co-educational schools (both boys and girls) students perceived twelve concepts as difficult the standard deviation of single sex, (boys only) ranged from 0.59-0.88, single sex (girls only) ranged from $0.53-0.78$ and that of co-educational school (both boys and girls) ranged from 0.62-0.79.

Research Question four: Does school location influence students' perception of difficult concepts in chemistry syllabus at SSCE level?

Table 4 was used to answer this research question.

Table 4 revealed the influence of school location on the students' perception of chemistry concepts in SSS3 chemistry syllabus by keeping up to the standard mean, between 1.76 and 3.00 as difficult; eleven concepts were perceived difficult by students in both rural and urban schools. The standard deviation of the scores of rural schools ranged from $0.49-0.80$ depicting a close relationship in their responses.

Testing Research Hypotheses

Research hypothesis one: Students, gender has no significant difference in the students' perception of difficult concepts in the senior secondary schools chemistry syllabus.

Table 5 showed that the mean of perception of difficult concepts for male students' was 1.98 while that of female students was 2.04. The t-cal was 0.101 which was less than the t-tab (1.96). This means that, there is a significant difference between the males and females students. Therefore, the null hypothesis was rejected.

Research hypothesis two: School nature has no significant influence on students' perception of difficult concepts in chemistry at secondary school level.

Table 4. Influence of location of school on students' perception of concepts in chemistry syllabus

\begin{tabular}{|c|c|c|c|c|c|c|c|}
\hline \multirow[b]{2}{*}{$\mathbf{S} / \mathbf{N}$} & \multirow[b]{2}{*}{ TOPICS OR CONCEPTS } & \multicolumn{3}{|c|}{ RURAL SCHOOLS } & \multicolumn{3}{|c|}{ URBAN SCHOOLS } \\
\hline & & $\mathbf{N}$ & MEAN & SD & $\mathbf{N}$ & MEAN & SD \\
\hline 1 & Separation of mixture & 23 & 1.48 & 0.59 & 175 & 1.49 & 0.65 \\
\hline 2 & Particulate nature of matter & 23 & 1.30 & 0.56 & 175 & 1.66 & 0.76 \\
\hline 3 & Symbol, formulae and equation & 23 & 1.74 & 0.54 & 175 & 1.85 & 0.74 \\
\hline 4 & Chemical combination & 23 & 1.70 & 0.76 & 175 & 1.69 & 0.70 \\
\hline 5 & Gaseous state & 23 & 1.52 & 0.67 & 175 & 1.61 & 0.71 \\
\hline 6 & Acids, base and salts & 23 & 2.22 & 0.74 & 175 & 1.71 & 0.70 \\
\hline 7 & Carbon and its compounds & 23 & 1.70 & 0.56 & 175 & 1.74 & 0.71 \\
\hline 8 & Organic chemistry & 23 & 2.04 & 0.71 & 175 & 1.85 & 0.79 \\
\hline 9 & Periodic table of element & 23 & 1.48 & 0.73 & 175 & 1.71 & 0.74 \\
\hline 10 & Structure\& energy of atom & 23 & 2.17 & 0.72 & 175 & 2.35 & 0.73 \\
\hline 11 & Quantitative analysis & 23 & 2.52 & 0.67 & 175 & 2.20 & 0.76 \\
\hline 12 & Rate of chemical Reaction & 23 & 2.00 & 0.52 & 175 & 1.68 & 0.75 \\
\hline 13 & Chemical Equation & 23 & 1.96 & 0.77 & 175 & 1.94 & 0.73 \\
\hline 14 & Non metal \& their Compounds & 23 & 1.78 & 0.80 & 175 & 2.20 & 0.77 \\
\hline 15 & Thermo chemistry & 23 & 2.65 & 0.57 & 175 & 2.47 & 0.70 \\
\hline 16 & Metals and their compounds & 23 & 1.74 & 0.75 & 175 & 2.18 & 0.74 \\
\hline 17 & Applied chemistry & 23 & 2.70 & 0.63 & 175 & 2.49 & 0.70 \\
\hline 18 & Nuclear chemistry & 23 & 2.61 & 0.7 & 175 & 2.30 & 0.78 \\
\hline 19 & Astronomical chemistry & 23 & 2.83 & 0.49 & 175 & 2.62 & 0.67 \\
\hline
\end{tabular}

$\mathrm{N}=$ no of Respondents, SD = Standard deviation.

Table 5. t-test difference on the influence of gender on students' perception of difficult concepts in chemistry

\begin{tabular}{cccccccc}
\hline GENDER & $\mathrm{N}$ & Mean & SD & DF & t-cal & t-tab & Remark \\
\hline Male & 99 & 1.98 & 0.27 & 196 & 0.101 & 1.96 & Significant, \\
Female & 99 & 2.04 & 0.24 & & & & Null Hypothesis rejected \\
\hline
\end{tabular}

Not significant at 0.05 level.

Table 6. ANOVA differences on the influence of school nature on students' perception of difficult concepts in chemistry at secondary school level

\begin{tabular}{lcccccc}
\hline SCHOOL NATURE & Mean & Df & Mean Square & t-cal & t-tab & Remark \\
\hline Between Groups & & 2 & 0.05 & 0.47 & Significant, \\
Within Groups & 13.3 & 195 & 0.07 & Null Hypothesis rejected \\
Total & 13.41 & 197 & & \\
\hline
\end{tabular}

Not significant at 0.05 level. 
Table 7. t-test difference on the influence of school location on students' perception of difficult concepts in chemistry at secondary school level

\begin{tabular}{ccccccccc}
\hline Groups & $\mathrm{N}$ & Groups & Mean & SD & Df & t-cal & t-tab & Remark \\
\hline Rural & 23 & Schools & 1.99 & 0.18 & 196 & 0.79 & 1.96 & Significant, \\
Urban & 175 & Schools & 2.01 & 0.27 & & & & Null Hypothesis rejected \\
\hline
\end{tabular}

Table 6 showed that the mean square of perception of difficult concepts between groups in the single sex school students was 0.05 and that within groups in co-educational school students were 0.07 . The t-calculated was 0.47 which was less than the t-tab at 0.05 significant levels. This means that, there is a significant difference between the two groups in the single sex (i.e. boys only or girls only) schools students' perception and the co-educational school students. Therefore, the null hypothesis was rejected.

Research hypothesis three: School location has no significant influence on students' perception of difficult concepts in chemistry at secondary school level.

Table 7 showed that the mean of perception of difficult concepts for students in the rural schools was 1.99 while that of students in the urban schools is 2.01. The t-calculated is 0.79 which was less than the t-tab (1.96) at 0.05 significant levels. This means that, there is a significant difference between the rural and urban students. Therefore, the null hypothesis was rejected.

\section{Discussion of Findings}

Table 1 showed that the respondents perceived twelve concepts out of nineteen major concepts in the secondary school chemistry syllabus as difficult concepts. These concepts are: symbols, formulae and equations, acids, bases and salts, organic chemistry, structure and energy level of atom, quantitative analysis, chemical equation, non metal and their compounds, thermo chemistry, metals and their compounds, applied chemistry, nuclear chemistry and Astronomical chemistry. Finding from this study revealed that the chemistry students perceived more than half (63.2\%) of the senior secondary school concepts difficult learn. Perhaps the low performance of chemistry students at the SSCE level may not comprise since they found most of the concepts in the syllabus difficult to understand. The outcome of this study is in agreement with that of $[3,4,5,14]$ who found that students had difficulties in comprehending chemistry concepts.

Table 2 revealed the influence of students' gender on perception of chemistry concepts. The males perceived fifteen $(78.95 \%)$ concepts in the SSS3 chemistry as difficult. These concepts include: particulate nature of matter; symbols, formulae and equations; acids base and salts; carbon and its compounds; organic chemistry; structure and energy level of atom; quantitative analysis; chemical equation; non-metals and their compounds; thermo-chemistry; metals and their compounds; applied chemistry; nuclear chemistry and astronomical chemistry. While the females' perceived eleven (57.89\%) concepts as difficult. These concepts include: symbols, formulae and equations, organic chemistry, structure and energy level of atom, quantitative analysis, chemical equation, non-metal and their compounds thermo chemistry, metals and their compounds, applied chemistry, nuclear chemistry and astronomical chemistry. This study is in agreement with that of [11] who found that gender differences influence perception of science concept but contradicts that of [4] and [1] who found that there was no significance difference between male and female chemistry students in their perception of difficult concepts in chemistry.

Table 3 showed the influence of school nature on the students' perception of chemistry concepts such as: matter, symbols, formulae and equations, gaseous state, acids, bases and salts, carbon and its compounds, periodic table of elements, structure and energy level of atom, quantitative analysis, rate of chemical reaction, chemical equation, non-metals and their compounds, thermo chemistry, metals and their compounds, applied chemistry, nuclear chemistry, and astronomical chemistry. While the single sex (girls only) students' perceived thirteen concepts as difficult, which were:- symbols, formulae and equations, carbon and its compounds, organic chemistry, periodic table of elements, structure and energy level of atom, quantitative analysis, chemical equation nonmetals and their compounds, thermo chemistry, metals and their compounds, applied chemistry, nuclear chemistry and astronomical chemistry. Meanwhile, students in the co-education schools perceived twelve concepts as difficult. These concepts were:- symbols, formulae and equations, acids, bases and salts, organic chemistry, structure and energy level of atom, quantitative analysis, chemical equation, non metal and their compounds, thermo chemistry, metals and their compounds, applied chemistry, nuclear chemistry and astronomical chemistry. Since they perceived difficulty of concepts $n$ single sex schools students is higher than that in the co-educational schools made by [6] that single sex schooling should be encourage among students at the secondary school level.

Table 4 revealed the influence of school location on the students' performance of difficult chemistry concepts. The mean value between; 1.76-3.00 was considered as difficult and students in the urban schools also perceived eleven concepts to be difficult. Table 5, Table 6 and Table 7 showed the t-test values differences on the influence of gender, school nature and school location on students' perception of difficult concepts in chemistry at secondary school level respectively. The t-cal values in all the three variables were less than the t-tab value in each of the tables; therefore the null hypotheses was rejected in all of the cases. Meaning that, there was a significant influence of gender, school nature and school location on the perception of students' conceptual difficulties in chemistry which contradicts the earlier studies by $[4,5]$.

\section{Conclusion and Recommendations}

Based on the discussion of the findings, it could therefore be concluded that majority of the concepts (63.2\%) in the Nigerian chemistry curriculum were perceived as difficult to comprehend by high school 
college students. The study also revealed that the students' gender, school location and school nature have influence on perception of difficult concepts in chemistry syllabus.

The study has helped us to understand poor performance of students in chemistry in examinations such as WAEC, NECO, and NABTEB etc is due to their inability to comprehend most of the concepts in the subject. The study has also helped us to understand that the gender of students, school nature and location have influence on the students' perception of difficult concepts in the chemistry syllabus.

Emanating from the discussion of the findings, it is therefore recommended that the senior secondary school certificate chemistry syllabus be reviewed by examination bodies such as WAEC, NECO and NABTEB. More time should also be allocated to chemistry for effective teaching of the identified difficult concepts and usage of student-oriented practical activities, as this would help to concretize learnt concepts and reduce poor performances of students in both internal and external examinations.

Furthermore, male and female students should be guided and counseled properly before enrolment into science class which should be gender-friendly. The single-sex school should be merged into co-educational schools so as to encourage students' participation and sharing of ideas. In addition, students in rural and urban areas should improve in their study habits.

\section{References}

[1] Agogo, P. O \& Onda, M. O (2014). Identification of Students Perceived Difficult Concepts in Senior Secondary School Chemistry in Oju Local Government Area of Benue State, Nigeria. Global Educational Research Journal. 2(4): 44-49.

[2] Federal Republic of Nigeria (2013). National Policy on Education. $6^{\text {th }}$ Edition, NERDC Press Yaba, Lagos, Nigeria.
[3] Gongden J.J, Gongden. E.J \& Lohdip Y.N (2011). Assessment of the difficult areas of the senior secondary two chemistry syllabus of the Nigeria science curriculum. AJCE I (1): 48-58.

[4] Jack, G.U. (2005). Comparative difficult study of teachers' and students' perceptions of difficulty levels of topics in secondary school chemistry. An unpublished M.Ed. Dissertation: Delta State University, Abraka.

[5] Jimoh A.T. (2003). Chemistry topics in the senior school chemistry curriculum as perceived different by in-service Net Teachers. Nigeria Journal of Educational studies and Research, 4(1): 64-69.

[6] Kurumeh M.S, Igyu C.O, \& Mohammed A.S (2013). Influence of secondary school types on the achievement area of Benue State, Nigeria. Prime Research on education. 3 (1): 408-412.

[7] Nicoll, G. (2001). A Report of Undergraduates' Bonding Alternative Conceptions, International Journal of Science Education, 23(7): 707-730.

[8] Njoku Z.C \& Nzewi U.M. (2010). Difficulties experienced in the learning of electro chemistry Concept by students of different cognitive styles. The STEM fest Journal, Department of science education, University of NSUKA, 1-11.

[9] Obomanu B.J (2012). Student conceptual difficulties in electrochemistry in senior secondary Schools. Journal of Emerging Trends in Educational Research and policies studies 3 (99-102).

[10] Oyedokun, M.R. (2002). Identification of difficult topics in the senior secondary school certificate Biology syllabus as perceived by students. The Nigerian Teachers Today, 10(1\&2): 109-118.

[11] Philips, C.O. (2002). Gender difference in business mathematics reference in continuous assessment and final examination in tertiary institution in Niger State. Nigeria Journal of Gender and Development, 3(2): 474-478.

[12] Taber, K. S., (2002). Alternative Conceptions in Chemistry: Prevention, Diagnosis and Cure? London: The Royal Society of Chemistry.

[13] Uchegbu, R.I., Anozieh, M.C., Mbadiugha, C.N, Ibe, C.O, \& Njoku P.C. (2015). Teachers' Perception of the Impediments to Chemistry Teaching in Secondary Schools in Imo State, Nigeria. Open Science Journal of Education. 3(5):26-31.

[14] Uchegbu, R.I. Oguoma, C.C., Elenwoke, U.E. \& Ogbuagu, O.E. (2016). Perception of Difficult Topics in Chemistry Curriculum by Senior Secondary School (II) Students in Imo State. AASCIT Journal of Education. 2(3):18-23.

[15] WAEC (2014). Chief examiner's report. Lagos: WAEC Press Ltd.

[16] WAEC (2015). Chief examiner's report. Lagos: WAEC Press Ltd. 